\title{
Methane Isotherms and Magnetic Resonance Imaging in Shales
}

\author{
M. J. Dick ${ }^{1, *}, D$. Heagle $^{2}, D$. Veselinovic $^{1}$ and $D$. Green $^{1}$ \\ ${ }^{1}$ Green Imaging Technologies, Fredericton, NB, Canada \\ ${ }^{2}$ Natural Resources Canada, Canmet Energy - Ottawa, ON, Canada
}

\begin{abstract}
Adsorption isotherms of light hydrocarbons on reservoir rocks are key data used to quantify the total gas content in reservoirs and isotherms are now being used to improve our understanding of the processes affecting subsurface gas flow associated with gas injection from Enhanced Oil Recovery techniques. This project combined elements of the traditional pressure-volume gas adsorption isotherm technique and an NMR-based adsorption isotherm approach to determine the adsorption isotherms of light hydrocarbons on to tight rocks from oil and gas reservoirs. The new approach allows isotherms to be derived from NMR data. First, a $T_{2}$ distribution of the gas is determined over a range of gas pressures. Next, the volume of pore gas is estimated using the pore volume of the rock and the Van der Waals gas equation. The adsorbed gas content is then calculated by subtracting pore gas content from the total gas content. This is repeated for a range of gas pressures to determine the adsorption isotherm. This project used the NMR method described above and measured the gas pressure decay in the NMR cell. This combined approach includes the advantages of the NMR method but it also produces a pressure-time curve that can be used to identify when equilibrium is attained in low permeability rocks and can be used to compare adsorption kinetics of different gases. The advantages of our approach are that 1) the samples remain intact and the measurements provide information on the pore size distribution; 2) analyses can be carried out at reservoir pressures; 3 ) isotherms can be measured for any gas containing hydrogen atoms; and 4) the results can be used to examine the processes controlling gas flow through the rock. Future work to develop this technique will improve our quantification of the amount of pore gas in the cell, which will improve our partitioning between adsorbed gas and pore gas as well as allow for an improved analysis of the pressure response of the sample after degassing.
\end{abstract}

\section{Introduction}

Adsorption of gases to rocks is an important process for evaluating natural gas resource potential, coalbed methane recovery, as well as secondary and tertiary enhanced oil recovery techniques. State-of-the-art models are used to evaluate resource potential and enhanced oil recovery but these models require inputs including gas transport processes and adsorption isotherms to help describe the mobility and storage of gasses on the rocks. Gas transport through low-permeability rock, also referred to as tight rock, is a significant factor for evaluating how much of a resource is recoverable and how effective gas injection into a tight reservoir might be. Gas transport by diffusion is a slow process while transport by advection, or Darcy flow, may be orders of magnitude greater. Assessing the contribution of each component to the gas flux requires sophisticated experiments at a variety of pressures and/or multiple gases and for the most part does not lend itself to routine analyses [1].

Adsorption isotherms for rocks commonly report data on the volume of gas contained within the pore space, referred to here as pore gas, and the gas adsorbed on to the surface of the pore walls referred to here as adsorbed gas. Our use of the term adsorbed gas is equivalent to the term excess gas that has been used in some other adsorption isotherm studies [2].

The quantity of pore gas and adsorbed gas is traditionally measured volumetrically using a system of two cells, a sample cell and a reference cell, which are separated by a valve. A crushed rock sample is placed in the sample cell and the reference cell is filled with a gas at a known pressure. The valve is opened and the gas from the reference cell expands into the sample cell and the pressures in the two cells equalize. The procedure is performed first with a non-adsorbing gas, such as helium, to determine the void volume, or free gas content, in the rock sample via the difference in temperature and pressure before and after opening of the valve between the two cells. Then the system is evacuated at below-atmospheric pressures to remove the gas, and the reference cell is filled with an adsorbing gas. The valve is opened again and the adsorbing gas expands into the sample cell, it will fill the void volume and adsorb on the sample. The amount of adsorption can be calculated by subtracting the free gas 
content. The expansion of the gases is repeated at numerous pressures to generate isotherms. The disadvantages of this method include 1) the sample is crushed for the measurement which alters the structure of the sample; 2) no information is acquired on the size of the pores occupied by the gas; and 3) many analyses do not examine the processes controlling gas flow through the rock.

Low Pressure Gas Adsorption (LPGA) is another technique used to determine adsorption isotherms, pore size distributions and surface area. This technique also uses dry powdered samples that are evacuated of all gas and cooled so that the equilibrium gases, typically $\mathrm{N}_{2}$ or $\mathrm{CO}_{2}$, can adsorb to the surface of the sample. After the absorbing gas is added to the sample the change in pressure over time is analyzed to determine the adsorption isotherm as well as the pore size distribution and surface area or the sample. There are disadvantages with this method that impact analysis of low permeability rock including drying and powdering the samples that may change the sample characteristics. Also, the isotherms are carried out at low pressures $(<20 \mathrm{psi})$ which prevents an analysis of the isotherms at reservoir conditions and the number of gas adsorption sites is related to the gas pressure [2] so conducting the isotherms at lower pressures may underestimate the adsorption capacity of a reservoir or source rock. Finally, the isotherms are not determined using methane or any of the other light hydrocarbon gases, so the interaction between the hydrocarbon gas and organics in the rocks may not be addressed with this method.

Measuring gas in shales is challenging with NMR due to the low hydrogen index of gas and the small pore volume of shales, both of which result in low NMR signal. However, with recent advances in NMR hardware, gas measurements in shales are possible. Low-field NMR can be used to measure gas isotherms with hydrocarbon gases of interest (e.g. methane or ethane), which is important for evaluating gas in place or determining adsorption of hydrocarbon gases during gas injection for Enhanced Oil Recovery (EOR) strategies [3]. The advantages of NMR measurements include 1) the samples remain intact and the measurements provide information on the pore size distribution; 2) analyses can be carried out at reservoir pressures; and 3) isotherms can be measured for any gas containing hydrogen atoms; and 4) the results can be used to examine the processes controlling gas flow through the rock.

Gas adsorption to nanoporous materials and shales have has been previously studied [4,5]. These studies showed it was possible to identify three distributions of methane including 1) methane adsorbed in the micropores, 2) adsorbed methane in fast exchange with the surrounding mesopore network, and 3) adsorbed methane in exchange with the interparticle void space of the adsorbent beds by characteristic relaxation times and pressure dependencies in the relaxation time distributions.
In this study we use low-field NMR to generate methane isotherms by measuring the total gas in the rock and distinguishing the amount of free gas and adsorbed gas in a rock. We calculate the pore gas volume using Van der Waals gas equation to determine the methane adsorption isotherm. We also combine pressure measurements with NMR measurements to carry out an initial assessment of the transport processes controlling gas flow in a shale.

\section{Method}

The method for determining gas isotherms from NMR data is as follows:

1) Record the $T_{2}$ distribution of the dry shale sample (95C for 7 days in vacuum oven) with 0 psi of methane. Shale samples often have NMR signal from organic content present in the rock and should not be included in the gas isotherm analysis. It is assumed that this signal will be invariant with methane pressure and should be subtracted from all subsequent $T_{2}$ distributions at higher methane pressures.

2) Equilibrate the sample at a range of methane pressures (i.e. 500, 1000, $1500 \mathrm{psi}$ etc.). At each pressure record the $\mathrm{T}_{2}$ distributions as a function of time. This is necessary as it will take time for the methane to fully penetrate all the pores of the sample. Continue to record the distributions until the observed NMR signal has stabilized.

3) Subtract the background ( 0 psi methane) echo train from each of the echo trains measured for the various pressures $\left(500,1000,1500\right.$ psi etc.) to account for the $T_{2}$ distribution of the rock and any liquids or gases present in the sample before the experiment began. Retrieve the observed methane signal from each background subtracted distribution by summing the area under each distribution. This will yield the observed methane content in units of equivalent water volume $(\mathrm{ml})$ as the NMR spectrometer has been calibrated using water.

4) Convert the observed methane content in units of equivalent water volume to gas content $\left(\mathrm{GC}\right.$ as $\mathrm{scm}^{3}$ of methane/ $\mathrm{cm}^{3}$ sample) of observed methane using the following equation:

$$
G C=\frac{P V T_{S T P}}{T P_{S T P} H_{\text {index }} V_{\text {bulk }}}(1)
$$

Where $\mathrm{P}, \mathrm{V}$ and $\mathrm{T}$ are the pressure (psi), volume $\left(\mathrm{cm}^{3}\right)$ and temperature $\left(307^{\circ} \mathrm{K}\right)$ of methane during the experiment. $\mathrm{H}_{\text {index }}$ is the hydrogen index of methane. $\mathrm{P}_{\text {STP }}$ and $\mathrm{T}_{\mathrm{STP}}$ are standard temperature and pressure (14.7 psi and $\left.292^{\circ} \mathrm{K}\right)$. $\mathrm{V}_{\text {bulk }}$ is the bulk volume $\left(\mathrm{cm}^{3}\right)$ of the core sample.

5) Plot the gas content measurements for each pressure of methane observed as a function of time. This plot should show that the gas content stabilizes over time. After stabilization, retrieve the gas content for each pressure and plot the gas content as a function of pressure. This will yield the total gas isotherm.

6) To retrieve the pore gas isotherm employ the pore volume of the core sample (measured in a separate NMR 
experiment with a $100 \%$ brine saturated sample) and the Van der Waals gas equation and the compressibility of methane were used to calculate the pore gas content $\left(\mathrm{scm}^{3} / \mathrm{cm}^{3}\right)$.

$$
\text { Pore Gas Content }=\frac{P n T_{S T P} c}{P_{S T P} V_{b u l k} T}
$$

Where $\mathrm{P}$ is the pressure (psi) of the cell; $\mathrm{n}$ is the porosity (unitless) of the rock; $\mathrm{T}_{\mathrm{STP}}$ is the standard temperature $\left(292^{\circ} \mathrm{K}\right)$; c is the compressibility (unitless) of methane at $307^{\circ} \mathrm{K}$; $P_{\text {STP }}$ is the standard pressure (psi); $V_{\text {bulk }}$ is the bulk volume of the core; and $\mathrm{T}$ is the temperature $\left(307^{\circ} \mathrm{K}\right)$ of the magnet and cell. This assumes that the pore gas behaves like any standard gas in a container of fixed volume (i.e. an individual pore).

7) To retrieve the adsorbed gas isotherm subtract the pore gas isotherm from the total gas isotherm.

\section{Experiment}

The method for determining gas isotherms via NMR data was tested in three different experiments on three different shale samples. For the first two experiments, the NMR data was recorded on Oxford Instruments GeoSpec 2-75 rock core analyzer [6] equipped with Oxford Instruments P5 overburden NMR probe [7]. All data was then processed using GIT Systems Advanced software [8].

\subsection{Experiment 1}

The first experiment determined the gas isotherm for a Barnett shale (BN 1). The Mississippian Barnett Shale is an organic rich, thermally mature source rock for oil and gas produced from Paleozoic reservoir rocks in the Bend arch-Fort Worth Basin area of Texas [9]. Mean TOC for core samples averages between $4 \%$ and $5 \%$ [9] and a porosity of $6 \%$ [10]

Figure 1 shows the experimental setup employed for this experiment. Table 1 summarizes the properties of the sample while Table 2 summarizes the NMR parameters employed.

\begin{tabular}{|c|c|c|c|}
\hline Core Sample & BN 1 & LHSVL & Bakken \\
\hline Origin & Barnett & $\begin{array}{c}\text { Lower } \\
\text { Haynesville }\end{array}$ & Bakken \\
\hline $\begin{array}{c}\text { Core Diameter } \\
(\mathrm{cm})\end{array}$ & 3.81 & 2.51 & 2.49 \\
\hline $\begin{array}{c}\text { Core Length } \\
(\mathrm{cm})\end{array}$ & 4.79 & 2.57 & 1.67 \\
\hline $\begin{array}{c}\text { Bulk Volume } \\
\text { (mL) }\end{array}$ & 54.61 & 12.9 & 8.1 \\
\hline $\begin{array}{c}\text { Dry Core } \\
\text { Mass (g) }\end{array}$ & 129.16 & - & - \\
\hline $\begin{array}{c}\text { Pore Volume } \\
\text { (mL) }\end{array}$ & 2.60 & 1.137 & 0.19 \\
\hline Porosity (p.u.) & 4.76 & 8.80 & 2.3 \\
\hline
\end{tabular}

Table 1. Sample Information

\begin{tabular}{|c|c|c|c|}
\hline Measurement & $\begin{array}{c}\mathbf{T}_{2}, \mathbf{B N}- \\
\mathbf{1}\end{array}$ & $\begin{array}{c}\mathbf{T}_{\mathbf{2}}, \\
\text { LHSVL }\end{array}$ & $\begin{array}{c}\mathbf{T}_{2}, \\
\text { Bakken }\end{array}$ \\
\hline $\begin{array}{c}\text { Recycle delay } \\
(\mathrm{ms})\end{array}$ & 750 & 7500 & 2250 \\
\hline Tau $(\mu \mathrm{s})$ & 50 & 50 & 54 \\
\hline $\begin{array}{c}\text { Number of } \\
\text { Echoes }\end{array}$ & 5000 & 5000 & 13889 \\
\hline $\begin{array}{c}\text { Filter Width } \\
(\mathrm{kHz})\end{array}$ & 125 & 125 & 125 \\
\hline $\begin{array}{c}90^{\circ} \text { Pulse Length } \\
(\mu \mathrm{s})\end{array}$ & 7.5 & 9.31 & 6.63 \\
\hline $\begin{array}{c}180^{\circ} \text { Pulse } \\
\text { Length }(\mu \mathrm{s})\end{array}$ & 15.2 & 18.88 & 13.71 \\
\hline
\end{tabular}

Table 2. NMR Parameters

The experiment can be summarized as follows, sample BN 1 was confined hydrostatically with FC-40 (CAS Number 86508-42-1), and NMR-inert fluid, to a pressure of $2500 \mathrm{psi}$ in the overburden NMR probe. The system was examined for gas leaks but no obvious leak was detected. The probe was then inserted into the rock core analyzer. The sample was evacuated with a vacuum pump, then as received or dry $\mathrm{T}_{2}$ measurements were taken before the introduction of methane. Next, methane was introduced to the sample at $500 \mathrm{psi}$. $\mathrm{T}_{2}$ measurements were acquired at 2-minute intervals for the first hour, then at 15 minute intervals for the following 3 hours, and at 60 minute intervals for the remainder of the experiment. The pressure was continuously monitored via Arduino microcontroller [11]. The Arduino then reported the pressure to an internal website and a computer program running on our server logs all the system pressures. In addition, a Raspberry Pi [12] computer monitors the overburden pressure via the same internal website and turns a pump on or off depending if the overburden pressure was too high or too low. This ensured the overburden pressure remained constant throughout the experiment. The $\mathrm{T}_{2}$ measurements were then employed to retrieve the total gas content present in the rock as a function of time 


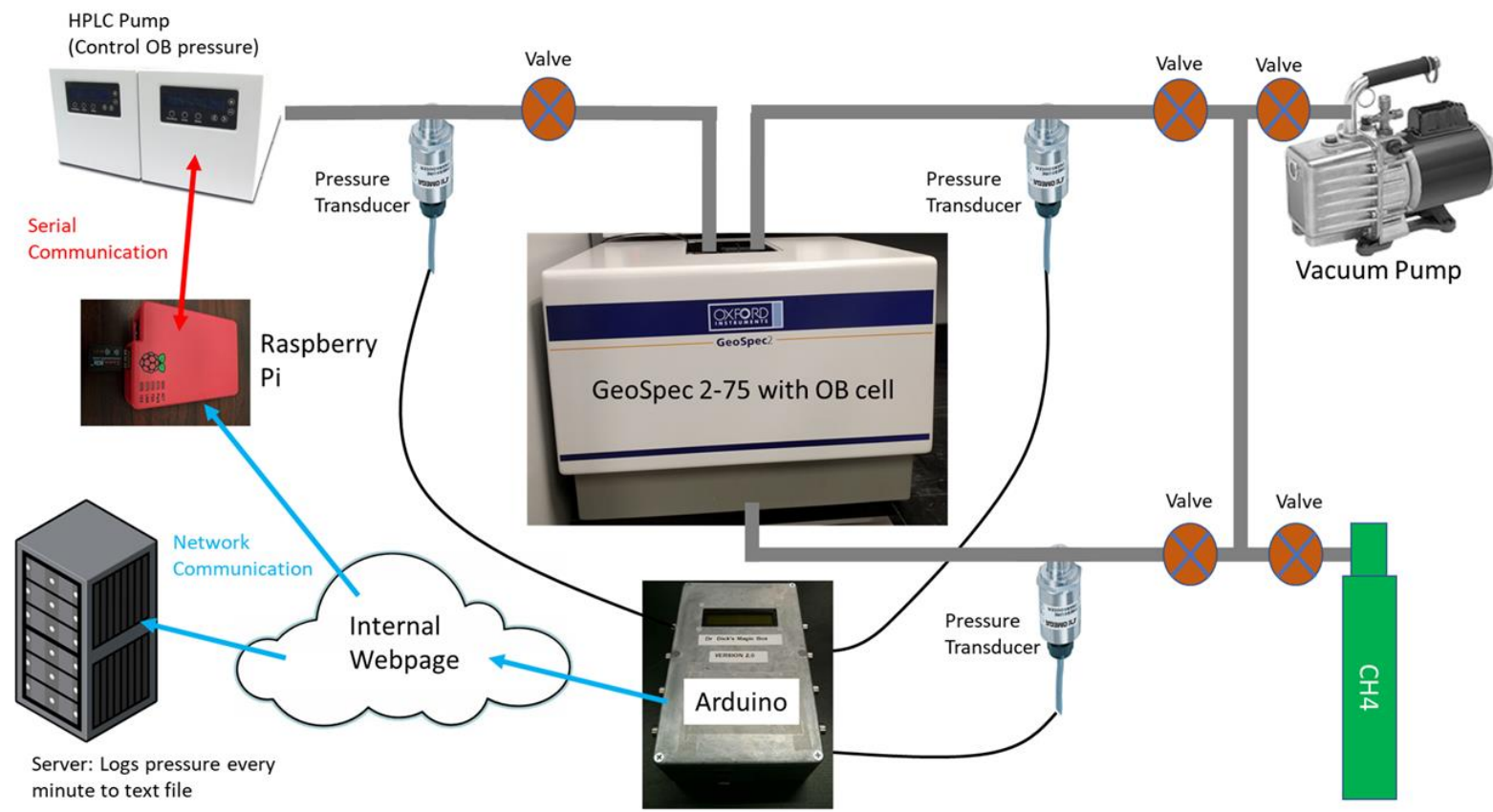

Figure 1 - Experiment 1 Setup

following the procedure outlined in Section 2 of this paper.

\subsection{Experiment 2}

The second experiment determined the gas isotherm for a Lower Haynesville shale (LHSVL). The Upper Jurassic Haynesville Shale is an organic- and carbonate-rich mudrock deposited in a deep-water environment on the margins of the Gulf of Mexico, with average porosities around $11 \%$. The average TOC of the Haynesville formation is $2.5 \%$ [13] with a range of $3 \%$ to $14 \%[14,15]$.

Table 1 summarizes the properties of the sample while Table 2 summarizes the NMR parameters employed. Sample LHSVL was not a solid core sample as sample $\mathrm{BN}$ 1. Instead this sample was made up of three irregularly shaped fragments (Figure 2).
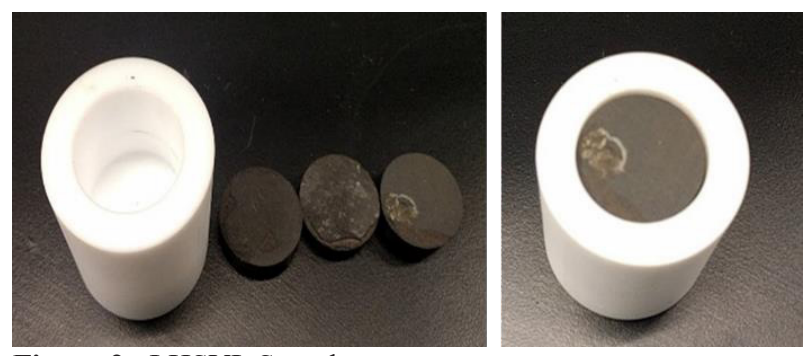

Figure 2: LHSVL Sample

Coring is an issue with most shale samples so the goal of this experiment was to prove that the NMR gas isotherm determination can be employed on samples regardless of shape including crushed and powdered samples. In order to get the fragments into the overburden probe a new Teflon holder with the same outer dimensions as a standard core sample was built. Previous testing with Teflon using a GeoSpec 2-75 rock core analyzer has shown the digital filters remove the fluorine signal, thereby removing the signal from the Teflon core holder from the results. As shown in Figure 2, the samples were then placed into the new holder. The holder and the samples were then placed into the overburden NMR probe and the probe then inserted into the rock core analyzer. As in Experiment 1, the sample was evacuated with a vacuum pump, then as received or dry $T_{2}$ measurements were taken before the introduction of methane. 


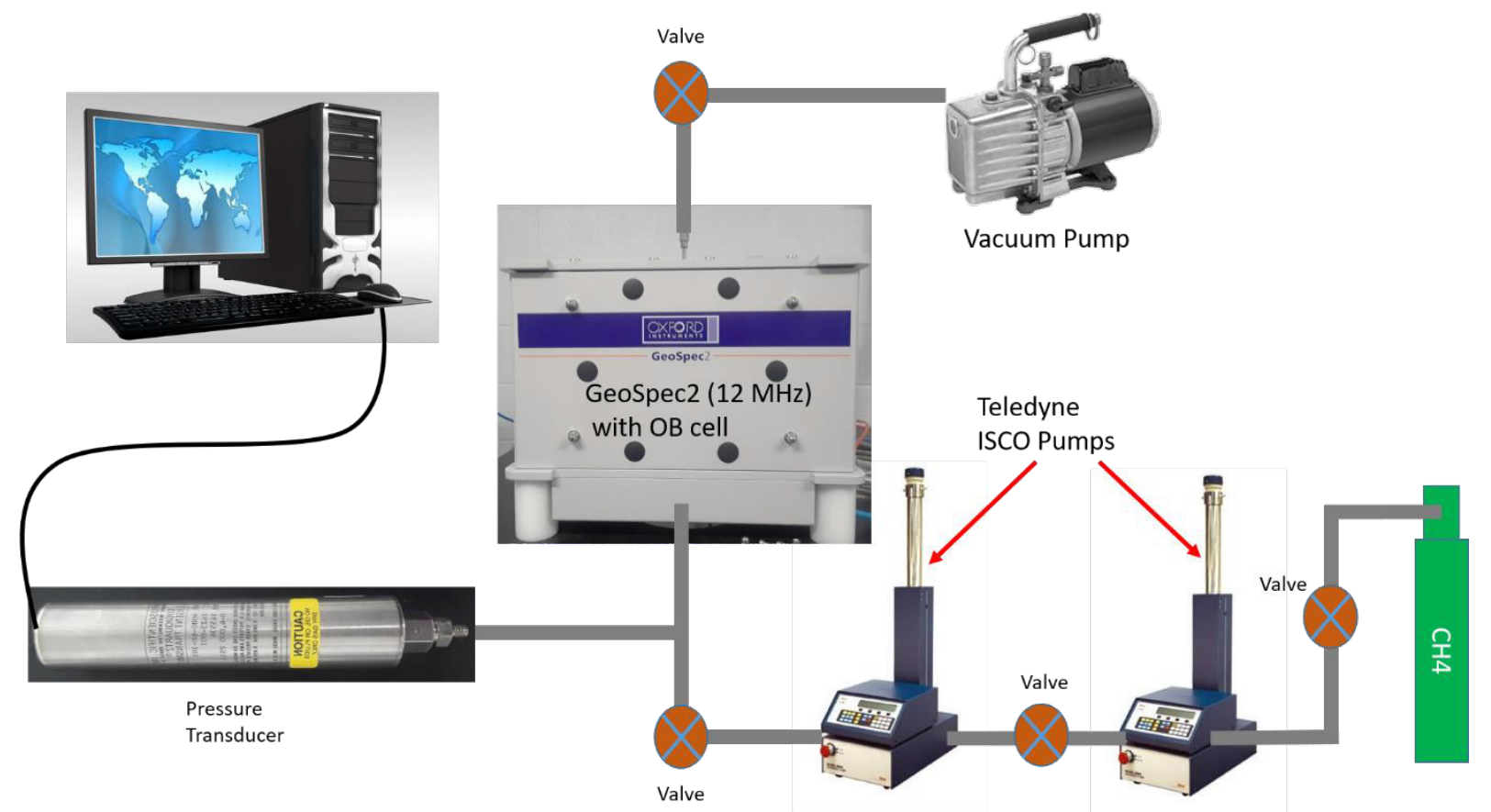

Figure 3: Experiment 3 Setup

No confining fluid was used in this experiment. Instead methane filled the confining volume of the probe. This simplified the experiment as it eliminated the need to use a second pump and an additional fluid as confining fluid. However, as a result of filling the probe with methane, the $\mathrm{T}_{2}$ distributions recorded at elevated methane pressures had large amounts of signal from free methane. As will be outlined in the Results section of this paper, this added a step to the gas isotherm determination method outlined in the previous section.

\subsection{Experiment 3}

The experimental design for experiment 3 (Figure 3) was similar to experiment 2 except the core sample was one solid piece of rock and the Teflon core holder was not used. Table 1 shows the rock sample properties for the Bakken core used in this experiment. The Bakken shale sample was collected from the Viewfield area in Saskatchewan, Canada. The Upper and Lower members of the Bakken are black organic-rich shales the Upper Member shale have average TOC of $17.6 \%$ with an average porosity of $3 \%$ [16].

The methane gas supply was connected to an ISCO $260 \mathrm{HL}$ pump and an ISCO 260D pump. The pressure in the overburden cell was controlled using the valves and the constant pressure setting of the ISCO pumps. Independent pressure measurements of the overburden cell were obtained using a Paroscientific 9000K model pressure transducer.

The overburden cell and sample were evacuated using a vacuum pump, then the initial NMR $\mathrm{T}_{2}$ distribution was obtained using an Oxford Instruments Geospec2 $12 \mathrm{MHz}$ rock core analyzer [17]. All data was again processed using GIT Systems Advanced Software. NMR parameters used for all $\mathrm{T}_{2}$ measurements are shown in Table 2. Adsorption isotherms were determined at the following pressures (psi): 242, 494, 997 and 1593. Adsorption isotherms were carried out by raising the pressure in the cell to the desired pressure, setting the pumps to the constant pressure, and monitored through the course of the experiment. The NMR $\mathrm{T}_{2}$ distributions were taken minutes apart for the first hour of the experiment and then hours apart as the experiment proceeded for 24 or more hours.

Following measurement of the gas isotherms for the Bakken sample, an experiment was completed examining the desorption isotherm of methane from the shale. This experiment was meant to improve our understanding of the processes controlling methane movement in the rock matrix. After the $\mathrm{T}_{2}$ data collection was completed at the highest pressure (1593 psi), the overburden cell was allowed to degas over a period of minutes and when the pressure in the cell reached atmospheric pressure, the cell was re-sealed using the valves. The pressure was monitored over the next several days and $T_{2}$ measurements were obtained over that time.

\section{Results}

The left-hand panel of Figure 4 shows three $T_{2}$ distributions recorded for sample BN 1. The black trace is the background or as received distributions recorded at 0 psi of methane. The red and blue traces were recorded with a methane pressure of $2000 \mathrm{psi}$, with the red trace recorded within minutes of methane being introduced to the sample, and the blue trace was recorded hours after the introduction of methane. As expected, the blue trace has more signal than the red trace as methane has more time to penetrate the pores of the sample. If there was free methane surrounding the core then a relatively large peak 
should be observed near $10^{3} \mathrm{~ms}$ (see LHSVL and Bakken results below).

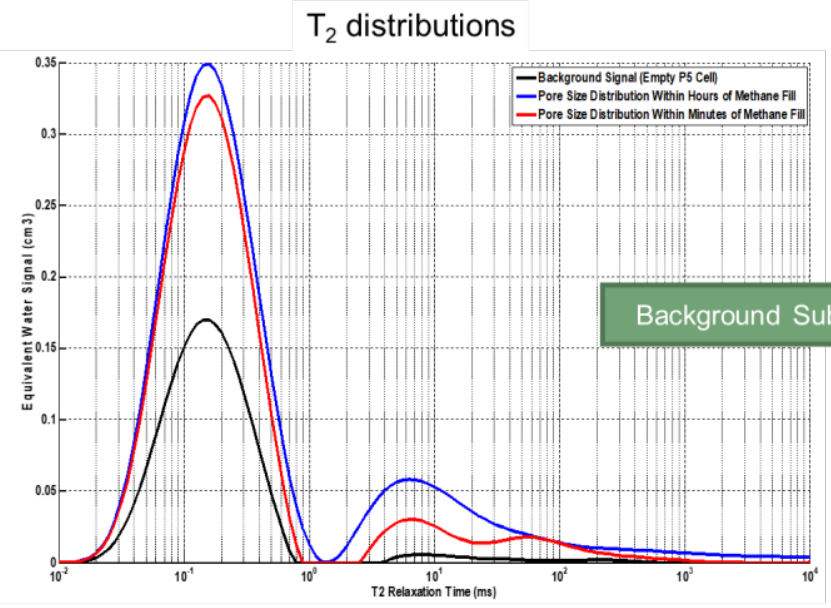

Figure 4: $T_{2}$ distributions For BN 1 Sample

The right-hand panel in Figure 4 shows the same $\mathrm{T}_{2}$ distributions as the right-hand panel, but with the background $\mathrm{T}_{2}$ distribution (black line in the right-hand
The average amount of methane after four hours was used to calculate the total gas isotherms for each pressure and is plotted as the blue trace in Figure 6. The green trace in Background Subtracted $\mathrm{T}_{2}$ distributions

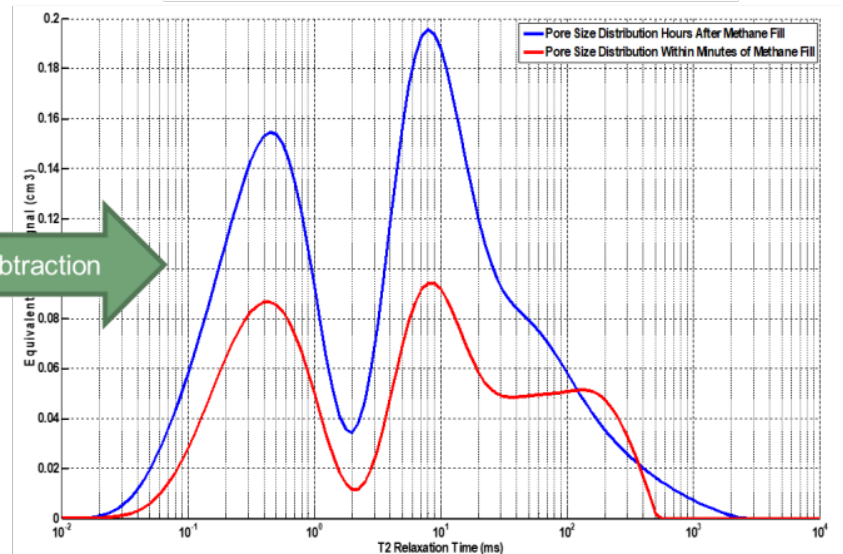

Figure 6 is the calculated pore gas isotherm using equation 2 above while the red trace is the adsorbed gas isotherm and is calculated as the difference of the total gas

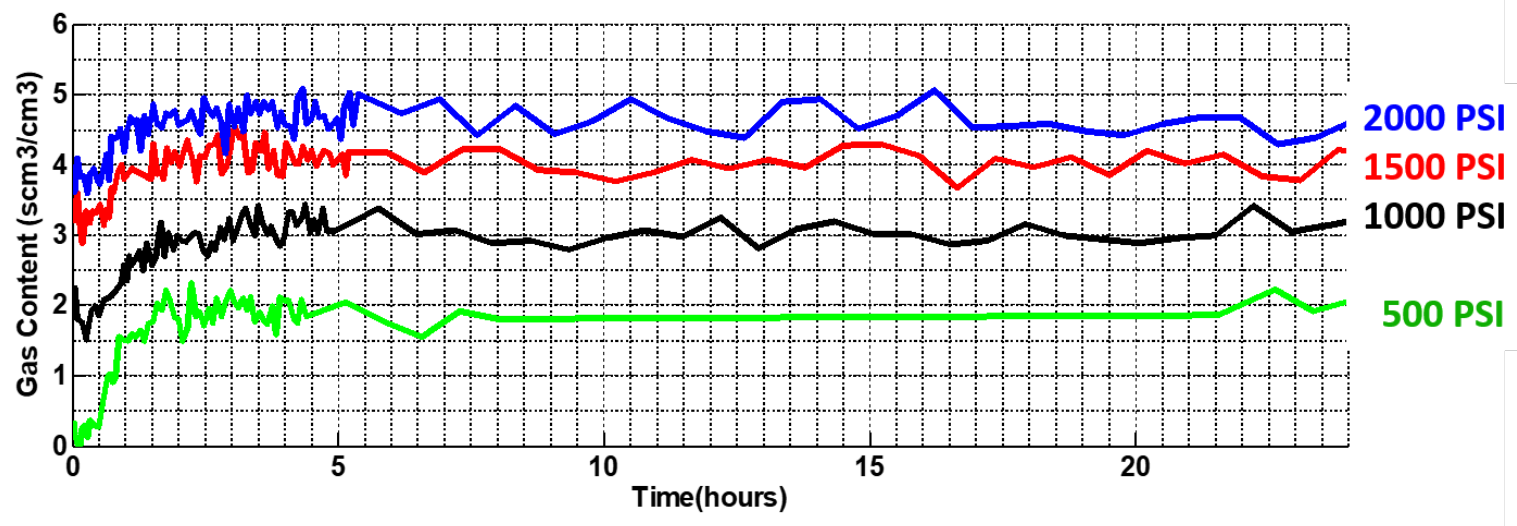

panel) subtracted. The bimodal distribution of the subtracted $T_{2}$ distributions shows methane occupying small pores $\left(\mathrm{T}_{2}<2 \mathrm{~ms}\right)$ and methane occupying relatively larger pores $\left(\mathrm{T}_{2}>2 \mathrm{~ms}\right)$. The area under each of the blue curve and the red curve is the methane content in units of equivalent water volume. These volumes are converted to methane gas content and plotted as a function according to Step 4 of the procedure outlined in Section 2 of this paper.

Figure 5 shows the plot of calculated gas content versus time for sample BN1. The figure shows that for each fill pressure of methane (green 500 psi, black 1000 psi, red $1500 \mathrm{psi}$, and blue $2000 \mathrm{psi}$ ) approximately 4 hours are required for methane to fully penetrate the pores of the sample and the amount of methane to stabilize. After 4 hours the measured gas content remained relatively constant $( \pm 1 \%)$. The variability in the gas contents decreases after 5 hours but this is likely due to a reduced sampling frequency. content and the pore gas content. Each were calculated according to the procedure outlined in Section 2 of this paper. The pore gas content increases relatively linearly with pressure and only deviates from linearity at higher pressures where its behaviour begins to deviate from the ideal gas law according of the Van der Waals equation. The adsorbed gas content on the other hand is not linear. The amount of adsorbed gas increases quickly at lower pressures due to the large number of adsorption sites still available but there are a finite number of adsorption sites available so the change in gas content with increasing pressure declines with increasing pressure. Finally, the total gas isotherm is simply the sum of the pore gas isotherm and adsorbed isotherms and has properties similar to each. The adsorbed methane content for BN1 reaches $1.3 \mathrm{scm}^{3} / \mathrm{cm}^{3}$ or $0.02 \mathrm{mmol} / \mathrm{g}$ of rock at $1500 \mathrm{psi}$, which is within the reported range of methane adsorption of 0.007 to $0.1 \mathrm{mmol} / \mathrm{g}$ [2]. 


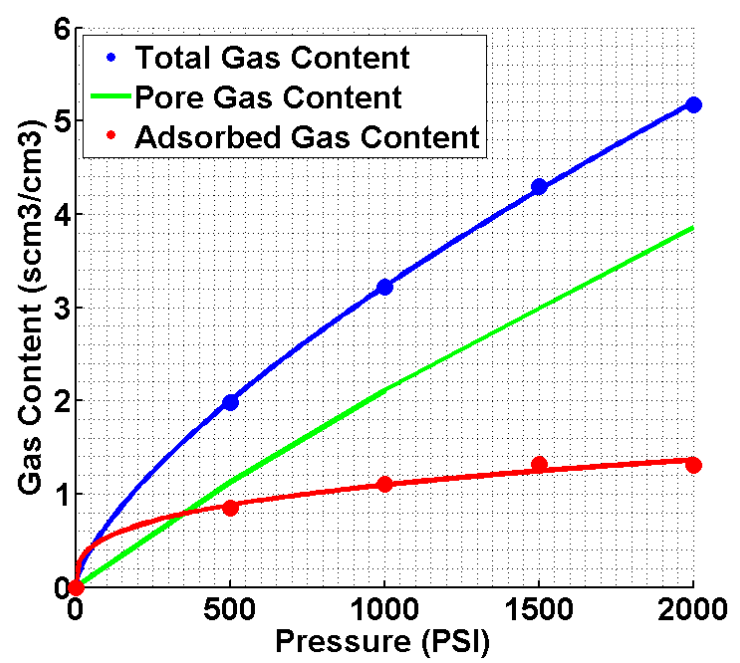

Figure 6: Gas Isotherm For Sample BN1

Figure 7 shows background subtracted $\mathrm{T}_{2}$ distributions recorded for the fragmented LHSVL sample. The blue trace shows the distribution recorded with a pressure of 500 psi of methane while the red trace shows the distribution recorded at a pressure of 2000 psi. As expected, there is more methane present in the sample at 2000 psi than at 500 psi. What is more interesting about Figure 7, is the large signals present at slow $\mathrm{T}_{2}$ (i.e. above $100 \mathrm{~ms}$ ). This signal is too late to be originating in the pores of the shale sample. Typical shales have $\mathrm{T}_{2}$ distributions with peak values around 0.1 to $10 \mathrm{~ms}$. These late $T_{2}$ peaks are instead due to free methane present in the experiment. This was further confirmed in a T1-T2 map in experiment 3 , where a large peak appeared at $\mathrm{T} 1$ $=\sim 1000 \mathrm{~ms}, \mathrm{~T} 2=\sim 1000 \mathrm{~ms}$ and it was assumed to be bulk methane. As mentioned in the previous section, there is significant free methane in the LHSVL experiment because the confining volume of the overburden probe was filled with methane. To calculate the gas isotherm analysis for this sample, the free methane was removed from the $\mathrm{T}_{2}$ distributions recorded at each pressure. From Figure 7, it is obvious that the removal of signal from free methane can be accomplished by simply applying a cut off to the $T_{2}$ distributions. For example, in Figure 7, only the signal below $223 \mathrm{~ms}$ (shown by the vertical green line) is included, which removes the free methane signal from the analysis. Once the distributions have the free methane signal removed, the gas isotherm calculation continues according to the method laid out in Section 2 of this paper.

The final gas isotherms generated from the NMR data for LHSVL are shown in Figure 8 and the shape of the curves are similar to what was observed in the BN 1 sample above. The adsorbed methane content for LHSVL reaches $4.0 \mathrm{scm}^{3} / \mathrm{cm}^{3}$ or $0.07 \mathrm{mmol} / \mathrm{g}$ of rock at $1500 \mathrm{psi}$, which is close to other reported data $0.09 \mathrm{mmol} / \mathrm{g}$ [18].

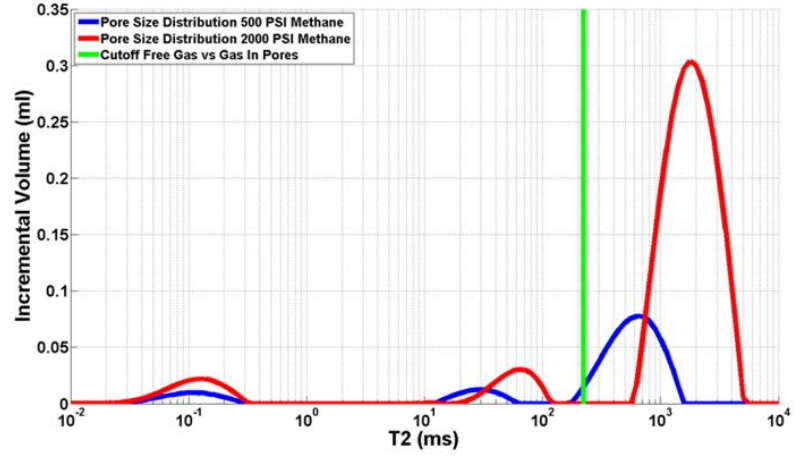

Figure 7: $T_{2}$ Distributions for Sample LHSVL

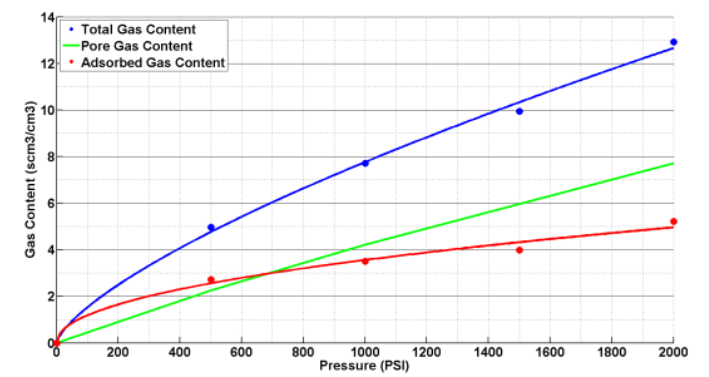

Figure 8: Gas Isotherm For Sample LHSVL

Figure 9 shows a background subtracted $\mathrm{T}_{2}$ distribution recorded for the Bakken sample at pressure of 1500 psi. $\mathrm{T}_{2}$ measurements ended before the relaxation was complete because the focus was on characterizing the signal between 0 and $100 \mathrm{~ms}$, the methane associated with the rock. The peak above $200 \mathrm{~ms}$ is caused by free methane and was removed to complete the gas isotherm analysis similar to the LHSVL sample described above.

Figure 10 shows the gas isotherm generated for the Bakken core, which is different from the two cores described above. The adsorbed gas content of the Bakken core is greater than the Haynesville core, which is likely due to the higher \%TOC in the Bakken core, and TOC preferentially adsorbs hydrocarbon gases. The pore gas content of the Bakken core is significantly lower than the other two cores. The adsorbed gas for the LHSVL sample was approximately $4 \mathrm{scm}^{3} / \mathrm{cm}^{3}$ at 1000 psi whereas the pore gas content at 1000 psi for the Bakken sample was approximately $1 \mathrm{scm}^{3} / \mathrm{cm}^{3}$. This is consistent with the lower porosity of the Bakken sample compared to the Hayneville sample (Table 1), which limits the volume available for pore gas. The adsorbed methane content for this Bakken core is $0.3 \mathrm{mmol} / \mathrm{g}$ of rock at $1500 \mathrm{psi}$, which is below the reported range of $\mathrm{CO}_{2}$ adsorption isotherms 1.0 to $3.5 \mathrm{mmol} / \mathrm{g}$ [19]. LPGA results for the Bakken were between 1.75 and $3.25 \mathrm{~cm}^{3} / \mathrm{g}$ [20], which is less than the adsorption reported here (approximately $7 \mathrm{scm}^{3} / \mathrm{g}$ ) but the LPGA analysis was carried out with $\mathrm{N}_{2}$ at nearly 1500 psi less than the experimental conditions here.

A review of the $\mathrm{BN}-1$, LHSVL and Bakken isotherms shows that the results are consistent with published literature and the distribution of peaks can be used to quantify methane in tight rocks. The results are limited at low pressures because the relatively small amount of 
methane is insufficient to produce a reliable signal, though the examination of hydrocarbon gases and source or reservoir rocks is typically carried out at higher pressures. Further work is also required to determine the accuracy of the pore gas content using Van der Waals equation as well as exploring employing a Langmuir isotherm to fit to the adsorption isotherm data.

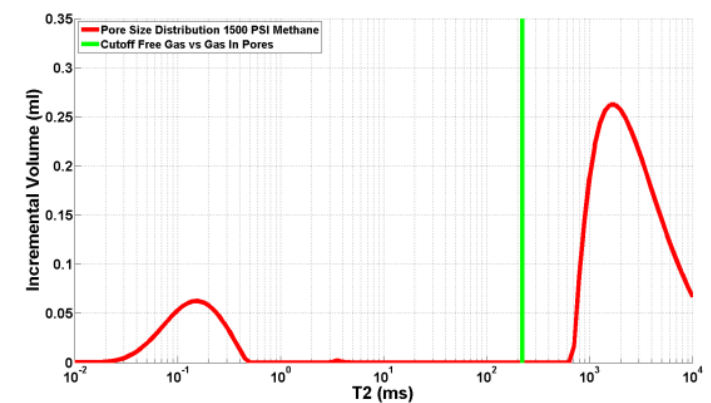

Figure 9: $T_{2}$ distribution At 1500 psi for Bakken Sample

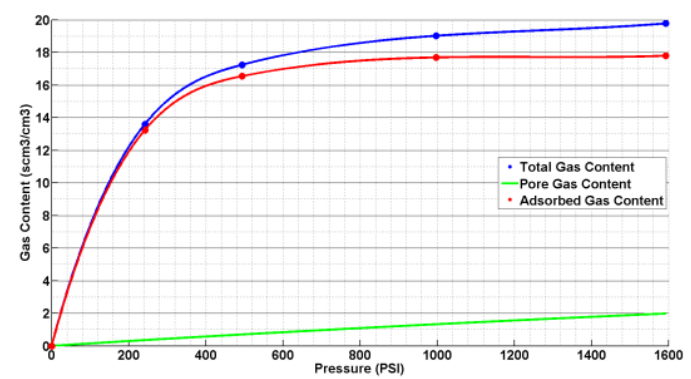

Figure 10: Gas Isotherm for the Bakken Sample

The experiments with the Bakken core continued beyond the measurement of the gas isotherm. $\mathrm{T}_{2}$ distributions were recorded as the core degassed. Figure 11 shows the final background subtracted $\mathrm{T}_{2}$ distributions recorded during the degassing stage of the experiment. The upper panel shows the $T_{2}$ distributions recorded on the same $y-$ axis scale as the data recorded with a pressure of $1500 \mathrm{psi}$ (Figure 9) where as the lower panel shows the $\mathrm{T}_{2}$ distributions plotted with a more reduced y-axis scale making it easier to see the peaks. Comparing the upper panel with Figure 9, it is obvious that the amount of gas in the pores (peak near $0.1 \mathrm{~ms}$ ) has been reduced during degassing but gas is still present. This methane signal is most likely now from residual adsorbed gas that is taking time to leave the pore walls.
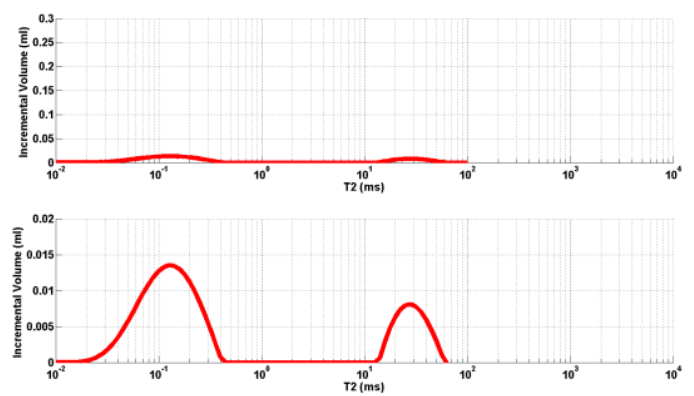

Figure 11: $T_{2}$ Distribution Measured For Bakken Sample at the End of Degassing

Further evidence that the methane signal is coming from residual adsorbed gas can be observed by plotting the total gas content determined from the NMR measurements during degassing as a function of time, which is presented in Figure 12. The amount of gas in the core declines to approximately $15 \mathrm{scm} / \mathrm{cm}^{3}$ in the first 12 minutes followed by a gradual decrease in total gas content. The methane is slowly moving out of the core. Once the methane is out of the core it is no longer present in the total gas content calculation as it becomes free methane and is removed from the calculations. The total gas content remains near $15 \mathrm{scm}^{3} / \mathrm{cm}^{3}$ after almost two days of degassing. Based on the isotherm (Figure 10), the remaining methane in the core is likely adsorbed to the pore walls but some methane may remain in the pores. .

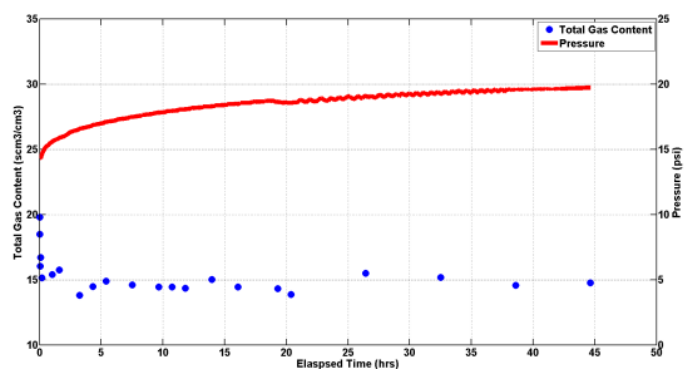

Figure 12: Total Gas Content and Pressure During Degassing for Bakken Sample

Further evidence of this degassing behavior can be interpreted from the experimental pressure that was recorded simultaneously with the total gas content and is also plotted in Figure 12. As expected, the pressure is increasing over time during degassing as the adsorbed gas leaves the pore walls where it does not contribute to measured gas pressure in the overburden cell and migrates to pore gas or free methane resulting in an increase in gas pressure in the cell. After the cell was opened, gas pressure declined to atmospheric pressure (14.3 psi) and increased during the degassing period to $19.7 \mathrm{psi}$. Future work will determine the volume of the NMR cell so that the declining core gas content can be compared to the rising cell pressure and an improved approach can be used to examine the transport processes controlling methane degassing from the core.

Another interesting result from Figure 11, is the appearance of a second peak between 10 and $100 \mathrm{~ms}$ that was not present during the gas isotherm measurement. We believe that this is signal from methane in a fracture within the core. This signal was not present in Figure 9 as the confining pressure was high enough (1500 psi) to close this fracture. Releasing the confining pressure during degassing has caused the fracture to open allowing gas from the smaller pores to migrate into it. In addition, if you look closely at Figure 9 you see a small peak at approximately $2.5 \mathrm{~ms}$. This small peak was present in all the $1500 \mathrm{psi} \mathrm{T}_{2}$ distributions recorded during the gas isotherm measurement and might be the same fracture as observed in the degassing experiment. At $1500 \mathrm{psi}$, the fracture would be closed leading to a decrease in the amount of gas in it and a decrease in its $\mathrm{T}_{2}$ relaxation time.

Figure 13 shows the total gas content of the core as it degases (blue circles) as well as the gas content of the first 
$\mathrm{T}_{2}$ peak (black circles) and the gas content of the second $\mathrm{T}_{2}$ peak from 10 to $100 \mathrm{~ms}$ (grey circles). The total gas content and gas content of the first $\mathrm{T}_{2}$ peak follow the same pattern. The first $T_{2}$ peak represents the majority of the gas in the core, which is corroborated by the larger $T_{2}$ peak in Figure 11. The first peak represents the adsorbed gas on the core and the gas in the small pores. The second $\mathrm{T}_{2}$ peak, contains less gas than the first peak, and increases over time. The higher $T_{2}$ value for this peak suggests this peak represents gas filling larger secondary porosity, possibly a fracture that developed in the core during the pressure-depressure cycle and that future degassing phases may need to be carried out at a slower rate to avoid the creation of such features. However, degassing at too slow a rate may miss important information regarding gas transport at early time.

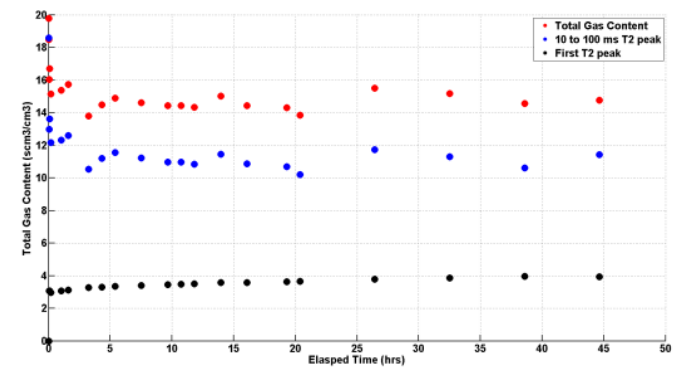

Figure 4: Calculated Total Gas Content For The Core Sample And Calculated Gas Content Both $\mathrm{T}_{2}$ Peaks Observed.

The change in the total gas content over time shown as blue circles in Figure 13 is the rate that methane adsorbed on to the core and methane in the pores of the core are able to escape the core. The calculated total gas content desorbed from the core was calculated by subtracting the total gas contents from the total gas content of the core at the completion of the 1593 psi adsorption isotherm (19.8 $\mathrm{scm}^{3} / \mathrm{cm}^{3}$ ) and are shown in Figure 14 as the experimental data.

The rate of methane loss from the core was examined using the diffusion equation shown by [21].

$$
Q(t)=Q_{t o t} \sqrt{1-e^{-B K t}}
$$

Where $\mathrm{Q}(\mathrm{t})$ is the desorbed gas content $\left(\mathrm{scm}^{3} / \mathrm{cm}^{3}\right)$ at time $\mathrm{t}(\mathrm{s})$; $\mathrm{Q}_{\mathrm{tot}}$ is the total desorbed gas content from the beginning of the experiment to the end; $B=4 \pi^{2} \mathrm{D} / \mathrm{d}^{2}$; and $\mathrm{D}$ the diffusion coefficient $\left(\mathrm{m} / \mathrm{s}^{2}\right) ; \mathrm{d}$ the radius of the sample (m); and $\mathrm{K}$ is a unitless correction factor. When the $\mathrm{B}$-value ranges between $6.58 \times 10^{-3}$ to $6.58 \times 10^{-6}$, which was the case for this work, the $\mathrm{K}$-value is 0.96 [21]. The calculated total degassed contents are shown as blue circles in Figure 14. The calculated gas loss by diffusion matches the pattern of the experimental data suggesting the equation is adequate to examine gas loss from the core. The diffusion coefficient used for this calculation was 2.6 $\times 10^{-9} \mathrm{~m}^{2} / \mathrm{s}$, which is significantly lower than $2.1 \times 10^{-5}$ $\mathrm{m}^{2} / \mathrm{s}$ for methane in air, but greater than the $10^{-12} \mathrm{~m}^{2} / \mathrm{s}$ values obtained for coal [21]. The calculated diffusion coefficient suggests that while diffusion may play a role in the rate of methane lost from the core, another process (e.g. advection) may be a significant process. This is not surprising given that at the beginning of the degassing phase the core was at least near equilibrium with 1593 psi and surrounded by atmospheric pressure, which should result in some amount of gas flow out of the core.

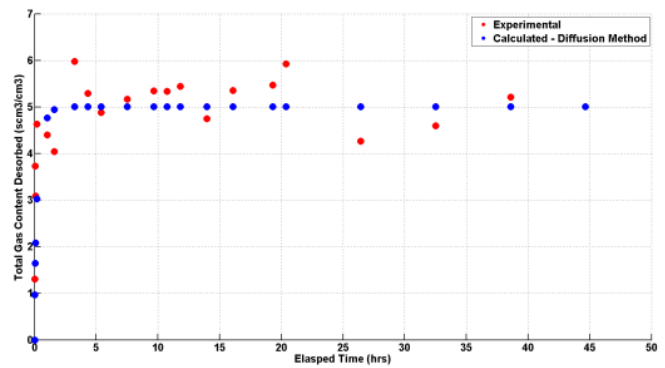

Figure 5: Total Gas Content $\left(\mathrm{scm}^{3} / \mathrm{cm}^{3}\right)$ Removed From The Core And Calculated Total Gas Content Removed From Core Using The Diffusion Equation.

\section{References}

[1] X. Cui, A.M.M. Bustin, and R.M. Bustin, "Measurements of gas permeability and diffusivity of tight reservoir rocks: different approaches and their applications," Geofluids, vol. 9, no. 3, Aug. 2009, doi: 0.1111/j.1468-8123.2009.00244.x.

[2] M. Gasparik, P. Berier, Y. Gensterblum, A. Ghanizadeh, B.M. Kroos and R. Littke, "Geological controls on the methane storage capacity in organicrich shales," Int. J. Coal Geol., vol. 123, no. 1, pp 3451, Mar. 2014, 10.1016/j.coal.2013.06.010.

[3] T. Alexander, J. Baihly, C. Boyer, B. Clark, G. Waters, V. Jochen, J. Le Calvez, R. Lewis, C.K. Miller, J. Thaeler, and B.E. Toelle, "Shale Gas Revolution," Oilfield Rev., vol. 23, no. 3, pp. 40-55, Sep. 2011.

[4] C. Horch, S. Schlayer, F. Stallmach, "High-pressure low-field 1H NMR relaxometry in nanoporous materials," J. of Magn. Reson., vol. 240, pp 23-33, Mar. 2014, doi: 1 0.1016/j.jmr.2014.01.002.

[5] Y. Liu, C. Wang, "Determination of the Absolute Adsorption Isotherms of $\mathrm{CH}_{4}$ on Shale with LowField Nuclear Magnetic Resonance," Energy Fuels, vol. 32, no. 2, pp. 1406-1415, Jan. 2018, doi: 10.1021 /acs.energyfuels.7b03428.

[6] Geo-Spec 2-75 Rock Core Analyzer User Manual, Version 1.8, Oxford Instruments, Tubney Woods, Abingdon, Oxon, UK, 2018.

[7] P5 Overburden Probe User Manual, Version 1, Oxford Instruments, Green Imaging Technologies, Oxford Instruments, Tubney Woods, Abingdon, Oxon, UK 2016.

[8] GIT Systems and LithoMetrix User Manual, Version 1.9, Green Imaging Technologies, Fredericton, NB, Canada, 2016.

[9] R.M. Pollastro, D.M. Jarvie, R.J. Hill, "Geologic framework of the Mississippian Barnett Shale, Barnett-Paleozoic total petroleum system, Bend 
arch-Fort Worth Basin, Texas," AAPG Bull., vol. 91, no. 4, pp. 405-436, doi: 10.1306/10300606008.

[10] K.A. Bowker, "Recent developments of the Barnett Shale play, Fort Worth Basin" W. Texas Geol. Soc. Bull., vol. 42, no. 6, pp 4-11. Art. No. 10126.

[11] Arduino Microcontroler Homepage, www.arduino.cc (accessed Feb. 1, 2018).

[12] Raspberry Pi Computer Homepage, www.raspberrypi.org (accessed Feb. 1, 2018).

[13] N.R. Jabri, "Chemostratigraphy and paleoenvironment of the Haynesville Formation, Harrison County, Texas," M.Sc. thesis, Geol. Dept., Univ. Houston, Arlington, Texas, 2013.

[14] F.P. Wang F.P. and U. Hammes, "Effects of reservoir factors on Haynesville fluid flow and production," World Oil, vol. 231, pp. D3-D6.

[15] U. Hammes, H.S. Hamlin, and E.E. Thomas, "Geologic analysis of the Upper Jurassic Haynesville Shale in east Texas and west Louisiana," $A A P G$ Bull., vol. 95, no. 10, pp. 1643-1666, Oct. 2011, doi: 10.1306/02141110128.

[16]L.K. Kreis, A.L. Costa and K.G. Osadetz, "Hydrocarbon potential of Bakken and Torquay formations, southeastern Saskatchewan," in Saskatchewan and Northern Plains Oil \& Gas Symposium C.F. Gilboy and S.G. Whittaker, Eds. 2006 , pp. 118-137.

[17]Bench-top Imager Hardware User Manual, Version 1.1, Oxford Instruments, Tubney Woods, Abingdon, Oxon, UK, 2006, pp. 1-32.

[18] A. Merkel, R. Fink and R. Littke, "The role of preadsorbed water on methane sorption capacity of Bossier and Haynesville shales," International J. Coal Geol., vol. 147-148, no.1, pp. 1-8, Aug. 2015.

[19] S. Kumar, "Rock-fluid interaction and phase properties of fluids in nano- and sub-nanopores of shales: sorption-based studies." Ph.D. dissertation, Dept. Petrol. Eng., Colorado School of Mines, 2016.

[20]Y. Liu, B. Shen, Z. Yan, P. Zhao, "Structure characterization and the controlling factors of the Bakken Formation," Energies, vol. 11, no. 11, pp. 2879-2894, Oct. 2018, doi: 10.3390/en11112879.

[21] G. Ni, B. Lin, C. Zhai, Q. Li, S. Peng, X. Li, "Kinetic characteristics of coal gas desorption based on the pulsating injection," Int. J. Min. Sci. Tech., vol. 24, no. 5, pp. 631-636, Sep. 2014, doi: 1 0.1016/j.ijmst.2014.03.023. 